\title{
Coupled Topology and Pipe Size Optimization of Water Distribution Systems
}

\author{
Salah H. A. Saleh ${ }^{1}$ and Tiku T. Tanyimboh ${ }^{2}$ \\ Department of Civil and Environmental Engineering, University of Strathclyde Glasgow. \\ 107 Rottenrow, Glasgow G4 0NG, UK
}

Salah H. A. Saleh, PhD Student

Department of Civil and Environmental Engineering, University of Strathclyde, Glasgow. 107 Rottenrow, Glasgow G4 0NG, UK.

Email: salah.saleh@strath.ac.uk

Tiku T. Tanyimboh, Senior Lecturer (Corresponding Author)

Department of Civil and Environmental Engineering, University of Strathclyde, Glasgow. 107 Rottenrow, Glasgow G4 0NG, UK.

Email: tiku.tanyimboh@strath.ac.uk;

Tel: + $44(0) 141548$ 4366;

Fax: + 44 (0) 1415532066

This article was published in Water Resources Management (2013), 27(14): 4795-4814. DOI: 10.1007/s11269-013-0439-4.

Water Resources Management

November 2013, Volume 27, Issue 14, pp 4795-4814, DOI: 10.1007/s11269-013-0439-4

Coupled Topology and Pipe Size Optimization of Water Distribution Systems

Salah H. A. Saleh, Tiku T. Tanyimboh

The final publication is available at www.springerlink.com;

http://link.springer.com/article/10.1007/s11269-013-0439-4/fulltext.html 


\title{
Coupled Topology and Pipe Size Optimization of Water Distribution Systems
}

\author{
Salah H. A. Saleh and Tiku T. Tanyimboh \\ Department of Civil and Environmental Engineering, University of Strathclyde, Glasgow. \\ 107 Rottenrow, Glasgow G4 0NG, UK
}

\begin{abstract}
This paper describes a new multi-objective evolutionary optimization approach to the simultaneous layout and pipe size design of water distribution systems. Pressure-deficient and topologically infeasible solutions are fully incorporated in the genetic algorithm without recourse to constraint violation penalties or tournaments. The proposed approach is demonstrated by solving three benchmark problems taken from the literature. New optimal layouts and/or new feasible solutions that are cheaper than the best solutions in the literature were found for both branched and looped network configurations. Specifically, a new best solution was generated for each of the above-mentioned benchmark problems. In addition, the case of the looped design of a hitherto branched network in the literature was considered. Detailed results are included that show that the proposed approach achieves good solutions efficiently and consistently.
\end{abstract}

Key words: water distribution system, topology optimization, penalty-free evolutionary approach, multi-objective optimization, genetic algorithm, EPANET 2

\section{Introduction}

Water distribution systems (WDSs) are a vital part of the infrastructure in developed societies. However, WDSs deteriorate with time and require periodic maintenance to maintain the system capacity at the required levels. This increases considerably the overall cost of the system. Even though the capital cost is made up of the costs of system components such as pipes, valves, tanks and pumps, the capital cost is mainly due to pipeline provision and construction (Djebedjian et al 2008). The operation cost is mainly due to energy and water treatment costs. Constructing and putting WDSs into operation is very expensive and it follows that good planning of the layout of the network of pipes can lead to a substantial reduction in the capital cost in addition to the long-term maintenance and operation costs.

WDSs can be either branched or looped. Branched systems have a structure similar to a tree. The main advantages of branched systems are that the capital 
cost is relatively low, they are easy to operate and are suitable for sparsely populated areas (Swamee and Sharma 2008). Branched systems have only one supply path from the source to any demand point (Swamee and Sharma 2008). This has the disadvantage of cutting off the water supply to the consumers downstream of any section of pipe that is not in service, e.g. due to a mains break. To reduce the effect of such situations, looped systems that have multiple supply paths from the source to the demand points are preferred. The reliability and cost of looped systems is highly dependent on the number of loops (Tanyimboh and Sheahan 2002; Tanyimboh and Setiadi 2008).

Most of the current investigations on WDS optimization have focused on designing a fixed layout. However, there are some situations in which designing a predefined layout is rarely optimal in real systems. For example, designing new systems or expanding existing systems where in general it will be impossible to determine the best configuration a priori. Determining the best layout is not only important for new systems. Expanding existing systems due to rehabilitation or upgrading purposes represents an opportunity to improve existing layouts, for example. Also, optimizing the layout of branched WDSs can achieve significant cost savings (Afshar 2007a). Despite the obvious benefits, joint layout and pipe size optimization has received little attention, probably because of the extra complexity involved (Morgan and Goulter 1985; Afshar 2007a) which in part is attributable to the strong coupling between the layout and pipe sizes.

Previous evolutionary approaches that optimized the layout and pipe sizes simultaneously considered mostly feasible solutions during the optimization process. Constraint violation penalties were designed to gradually exclude 
infeasible solutions from the optimization process. Moreover, the fact that penalty functions incorporate factors that are problem-specific made the previous studies time-consuming. Layout and pipe size optimization in such approaches is preceded by a trial and error procedure to design a penalty function that is valid only for the network under consideration. This has the disadvantage of being laborious when employing such approaches to design new WDSs. In addition, there is no guarantee that the designed penalty function is optimal.

This paper describes a new penalty-free multi-objective evolutionary approach to the simultaneous layout and pipe size optimization of WDSs. We adopted an approach in which the entire solution space that consists of both feasible and infeasible solutions is exploited in full. In particular, infeasible solutions are not targeted and removed arbitrarily purely by virtue of their infeasibility or by the use of extraneous penalties. The effectiveness of the approach is demonstrated by solving three benchmark problems. Better solutions than the best solutions in the literature were found for all the above-mentioned benchmark problems. By optimizing the layout and pipe sizes simultaneously and assessing infeasible solutions rationally, new least cost designs and/or new optimal layouts were found. In addition, a hitherto branched design optimization problem in the literature was solved as a looped design.

\section{LITERATURE REVIEW}

The problem of joint layout and pipe size optimization of WDSs has been the subject of a few studies. Rowel and Barnes (1982) developed a two-stage model that determined a least-cost branched layout first. Then, pipes to interconnect the branches of the network were added in the second stage. Morgan and Goulter 
(1982) developed an approach that contained two linear programs, one for determining the optimum layout and the other for pipe sizing. However, there was no guarantee that the designs generated would be fully looped as the criterion used was a simple requirement to connect each node using two pipes as opposed to two independent paths. Kessler et al. (1990) and Cembrowicz (1992) tackled the problem by choosing links for either addition or removal from a predefined base graph. The base graph is the network consisting of the full set of feasible links. All the above-mentioned approaches were based on an assumption that the problem could be divided into two separate optimization problems in which layout optimization is followed by pipe size optimization. However, the relationship between the layout and the pipe diameters is strong and sequential procedures as described above can be expected to yield suboptimal results.

More recently evolutionary optimization approaches have been attempted (Walter and Lohbeck 1993). For example, Davidson and Goulter (1995) proposed a method to optimize the layout of rectilinear branched networks. As no guarantee could be given for the feasibility of the designs obtained using genetic algorithm (GA) operators, two additional steps called recombination and perturbation were applied. Walters and Smith (1995) employed graph theory in an evolutionary algorithm for designing branched networks. Graph theory was combined with the conventional crossover and mutation operators to avoid the creation of infeasible designs in the reproduction process. Geem et al. (2000) employed a heuristic method called harmony search to optimise the design of branched networks. To avoid infeasible designs in the search process, a tree-growing algorithm starting from the base graph was used. 
Also, Afshar et al. (2005a) developed an iterative two-stage approach such that, in the first stage, the optimal diameters for a predefined layout are determined using a non-linear programming method. In the second stage, an iterative pipe removal search process is carried out to reduce the cost without undermining the node connectivity constraint. Any infeasible solutions generated in the early stages due to the randomness in creating the initial population of solutions by the GA are gradually discarded using constraint violation penalties. To ensure the feasibility of branched solutions, at least one independent path from the source nodes to each of the demand nodes is required. Afshar (2005b and 2007a,b) also proposed several approaches that basically restricted the evolutionary algorithms used to feasible solutions. These included a genetic algorithm using three modified roulette wheel selection schemes (Afshar 2007a), the conventional roulette wheel (Afshar 2007b) and a max-min ant algorithm (Afshar 2005b).

\section{MAIN HYDRAULIC EQUATIONS}

The performance of WDSs is governed by the following system of nonlinear equations.

$$
\begin{array}{ll}
\sum_{i j \in \text { in }\left(N_{j}\right)} Q_{i j}-\sum_{i j \in \text { out }\left(N_{j}\right)} Q_{i j}=Q_{j} & j=1, \ldots \ldots, N \\
\sum_{i j \in l} h_{i j}=0 & \forall l \\
h_{i j}=\alpha L_{i j}\left(Q_{i j} / C_{i j}\right)^{1.852} D_{i j}^{-4.871} & \forall i j \\
& \\
H_{j} \geq H_{j}^{\text {des }} & j=1, \ldots \ldots, N
\end{array}
$$


where $N=$ number of nodes; $l$ represents the set of pipes in the closed circuit of pipes that form a loop; $Q_{j}=$ demand or supply at node $j ; \operatorname{in}\left(N_{j}\right)$ and $\operatorname{out}\left(N_{j}\right)=$ all pipe flows to and from node $j$, respectively; $\alpha=$ dimensionless conversion factor (10.6844 in SI units); $C_{i j}, D_{i j}, h_{i j}, L_{i j}$ and $Q_{i j}=$ Hazen-Williams roughness coefficient, diameter, headloss, length and flow rate respectively for pipe $i j ; H_{j}$ and $H_{j}^{\text {des }}=$ actual and desired head respectively at node $j$. The desired head is the head at a node above which demands are satisfied in full. Equation (1) is for conservation of mass while Equation (2) is for conservation of energy; and Equation (3) is the Hazen-Williams pipe friction headloss formula. Equation (4) ensures there is sufficient pressure at each demand node. In the UK, for example, $H_{j}^{\text {des }}$ is often taken as a minimum residual pressure head of $15 \mathrm{~m}$ (Ofwat 2008). Equations (1) to (3) are usually handled by employing a hydraulic simulator -- e.g. EPANET 2 (Rossman 2000), EPANET-MSX (Shang et al. 2008), PRAAWDS (Tanyimboh and Templeman 2010), EPANET-PDX (Siew and Tanyimboh 2012), etc. -- which ensures these equations are automatically satisfied. Various approaches have been used in the literature to address Equation (4) in the design process. We developed a novel unified feasibility measure that accounts for both nodal pressures and network topology. This is explained in detail in the following section.

\section{PROBLEM FORMULATION}

A discrete combinatorial optimization problem with two objectives namely the capital cost and infeasibility both of which are minimized was developed. We used a novel unified feasibility measure that accounts for both nodal pressures and network topology. The optimization is considered under the following 
assumptions. (1) The network configuration including all of the feasible links is known. This network is termed the fully connected network herein. (2) The pipe diameters and the links to be included or excluded are the decision variables of the problem. The aim is to find and size the optimal subset of links. (3) Water demands are located at the nodes. In reality, demands occur along the pipes but for ease of analysis, they are aggregated and allocated at the nodes. (4) Node demands are known with certainty. Although nodal demands may be uncertain in practice, demands and other WDS aspects that can lead to uncertainty are not addressed herein. (5) The required pressure head at each demand node is given. (6) Finally, design is to be optimized based on the initial construction cost only. Even though the operational and other whole-life costs (Tanyimboh and Kalungi 2008) contribute significantly to the whole cost of the system, their inclusion is beyond this study.

If $c_{i j}$ denotes the cost per unit length for pipe $i j$, the cost objective function can be written as

$$
f_{1}=\text { Cost }=\sum_{i j} c_{i j} L_{i j}
$$

Any designs proposed should be both hydraulically and topologically satisfactory. This was addressed by ensuring there is a sufficient number of supply paths and sufficient pressure at all demand nodes. Firstly, the total shortfall in head for all demand nodes that have less than the desired head is 


$$
R H D=\sum_{\forall j: H_{j}<H_{j}^{d e s}}\left(H_{j}^{\text {des }}-H_{j}\right)
$$

in which $R H D$ is the residual head deficit for the entire network. In the case of a node having $H_{j} \geq H_{j}^{\text {des }}$, it is assigned a deficit of zero. In other words, the residual head deficit $R H D$ will be zero only if a design is feasible.

Secondly, to optimize the layout and pipe sizes simultaneously a pipe diameter of zero was introduced to enable different layouts to be generated by removing any link from the fully connected network (Afshar 2007b). A diameter of zero in Equation (5) yields zero cost, which reflects the real situation for a non-existent link. However, this results in an undefined value of the headloss in Equation (3). Therefore, to resolve this problem, the link removal case was modelled as a closed pipe when simulating the WDS. Since link removal takes place randomly especially in the early phases of the optimization, some nodes or even parts of the network can become disconnected from the source nodes. To avoid this, Equation (6) was extended to account for layout infeasibility. For a branched layout to be feasible, a minimum of one supply path is required for each demand node. For looped networks, at least two independent supply paths per demand node are required. The extent of layout infeasibility was quantified as the sum of the individual nodal shortfalls in the required number of independent supply paths. Accordingly, Equation (6) was augmented as follows.

$$
\begin{aligned}
& f_{2}=\text { Total Infeasibility } \\
& =\sum\left[\left(H_{j}^{\text {des }}-H_{j}\right)+\left(R-N P_{j}\right)\right] ; \forall j: H_{j}<H_{j}^{\text {des }} \text { and } \forall j: N P_{j}<R
\end{aligned}
$$


where $N P_{j}$ is the number of independent supply paths for node $j$ while $R$ is the minimum number of independent paths required. For a node with $N P_{j} \geq R$, the second term in Equation (7) is assigned a value of zero. $R=1$ for branched networks and $R=2$ for looped networks. The total infeasibility in Eq. 7 is equal to zero if and only if a design is both topologically and hydraulically feasible.

Due to the large difference in the respective ranges of the objective function values in Equations (5) and (7), each objective was normalized to maintain the objectives within the interval $[0,1]$, i.e.

$$
\frac{f_{i, j}-f_{i, \text { min }}}{f_{i, \text { max }}-f_{i, \text { min }}}
$$

in which $f_{i, \min }$ and $f_{i, \max }$ are the respective minimum and maximum values of the $i$ th objective function and $f_{i, j}$ is the value of the $i$ th objective function for the $j$ th candidate solution in the current population.

\section{COMPUTATIONAL SOLUTION}

The Non-dominated Sorting Genetic Algorithm NSGA-II (Deb et al. 2002) was employed. It is fast, robust and incorporates elitism. We have not provided an overview of NSGA II in this article. However, a detailed description is available in Deb et al. (2002). We employed simple binary coding (Goldberg 1989) and used fixed mapping in which each binary string is mapped to one of the decision variables of the problem. The hydraulic solver EPANET 2 was used to analyse the solutions the GA generated. 
It is worth observing that EPANET 2 often produces unrealistic results of node pressures and pipe flows within parts of the network that are not connected to a source. For example, isolated nodes are assigned arbitrarily large negative pressures while pipes having an isolated upstream node are dealt with as if they are connected to the source. We resolved this problem by developing an algorithm for detection of both isolated nodes and pipes that assigns zero flow and pressure, respectively, to any pipes and nodes that are not connected to a source. By addressing the problem of disconnected network components we were able to assess the fitness of both feasible and infeasible solutions in a consistent and biasfree manner.

We adopted a penalty-free strategy that enables infeasible solutions to participate fully in the optimization process. The reason for incorporating infeasible solutions is that in the latter stages some essential genes in the optimal solution may no longer be present in the current population of feasible solutions if, arbitrarily, some solutions are discarded purely because they are infeasible. This strategy also has the advantage of approaching the optimal design from both the feasible and infeasible regions of the solution space. In this way, the optimum design can be found by either lowering the cost of a near-optimal feasible design or converting a near-optimal infeasible design to a feasible design. The motivation is that optimal solutions for WDSs often occur at the boundary of the feasible region of the solution space. Figure 1 provides a diagrammatic overview of the proposed approach. 


\section{BENCHMARK EXAMPLES}

The two benchmark networks (Figure 2) considered are described briefly in turn in this section ahead of the results in Section 7. Both branched and fully-looped designs were considered for each of the two networks. A bit-wise mutation operator was used and mutation rates in the range 0.001 to 0.3 were investigated. This sensitivity analysis would appear to suggest that the optimum mutation rate is $p_{m} \approx 1 / n_{g}$ where $p_{m}=$ mutation rate and $n_{g}=$ chromosome length as determined by the number of genes. A Core 2 Duo desktop computer that has a processor speed of $2.99 \mathrm{GHz}$ and $3 \mathrm{~GB}$ of RAM was used.

Network 1 is a single source network made up of 9 nodes and 12 pipes as shown in Figure 2. The source located at node 9 has an elevation of $50 \mathrm{~m}$. All of the other nodes are demand nodes with an elevation of zero. The minimum desired head at all of the demand nodes is $30 \mathrm{~m}$. All of the pipes have a length of $100 \mathrm{~m}$ and Hazen-Williams coefficient of 130. The solution space for this network comprises $14^{12}=5.67 \times 10^{13}$ feasible and infeasible solutions, made up of 13 discrete pipe sizes plus the link removal option of diameter zero (Afshar 2007a). A 4-bit binary substring was used. This gave $2^{4}$ or 16 substrings of which two were redundant. The redundant substrings were mapped to the link removal option to increase the chances of creating new layouts. Since the network is composed of 12 pipes, each design is represented by a chromosome that has a 48-bit binary string. A singlepoint crossover operator was used to produce two offspring from two parents using a crossover probability of 1 . A bit-wise mutation operator was used to switch the selected bit either from 0 to 1 or from 1 to 0 . The mutation probability was $1 / n_{g}=1 / 48$, i.e. a $2.1 \%$ chance that any single bit would mutate. 
Network 2 (Figure 2) is part of the Winnipeg system (Morgan and Goulter 1985). This network has 2 sources, 20 nodes and 37 pipes. The Hazen-Williams roughness coefficient for all pipes is 130 . Allowing for pipe removal, the solution space of this network comprises a combined total of $14^{37}=2.55 \times 10^{42}$ hydraulically and/or topologically feasible and infeasible solutions. Using a 4-bit binary substring, since this network has 37 pipes, each solution was represented with a chromosome whose length is 148 genes. The resulting redundant codes from this representation were mapped to the link removal option. A uniform crossover operator was used to create two offspring from two parents using a crossover probability of 1 . Bit-wise mutation was used to flip the selected bit either from 0 to 1 or from 1 to 0 using a mutation probability of $1 / n_{g}=1 / 148$.

\section{RESULTS AND DISCUSSION}

The results for the four design problems are discussed below in turn. We have included indicative statistics for the consistency and quality of the solutions. In the results tables that follow, the relative frequencies of the various solutions found in multiple runs of the GA are displayed graphically in terms of the deviations of the respective costs from the cost of the best known solution. Given any number of random GA runs and their respective least cost solutions, the relative cost deviation of each solution is defined here as the ratio of the deviation of the cost to the maximum cost deviation among the solutions under consideration.

\subsection{BRANCHED DESIGN OF NETWORK 1}

Table 1 and Figure 3 show results of the achieved least cost branched design of Network 1. In all of the previous approaches the critical node was Node 1. It is Node 2 in the present optimal design (Figure 3). The small surplus head of $0.06 \mathrm{~m}$ 
at the critical node would appear to suggest that the achieved solution is at least a near-global optimum. Figure 4 shows the best achieved Pareto Optimal Front (POF) for Network 1. With reference to Equation (7), the maximum infeasibility value of $f_{2}=248$ (Figure 4 ) is the summation of the prescribed minimum nodal residual pressure head of $30 \mathrm{~m}$ and the minimum required nodal connectivity of $\mathrm{R}$ $=1$, for all the eight demand nodes, i.e. $(30+1) \times 8=248$. With a cost of zero this solution is always non-dominated. This zero cost solution has no pipes. Consequently, selecting the zero cost solution for crossover results in link removal in the offspring. This zero cost solution is very important as it safeguards the potential for creating new layouts in every generation.

Table 2 summaries the results to date and demonstrates clearly the effectiveness of the proposed approach. The best design generated costs $\$ 38,600$ and is actually the cheapest solution to date. The GA was run 10 times using different randomly created initial populations. A maximum of 200,000 function evaluations were allowed for each GA run. Using a population of 100, the optimum design having a cost of $\$ 38,600$ was identified in 8 different runs out of 10 . The best run took a CPU time of about 10 seconds after 10,400 function evaluations. The two remaining runs both found a feasible solution that costs $\$ 39,800$. The average, median and maximum value of the least cost for the $10 \mathrm{GA}$ runs were $\$ 38,840$, $\$ 38,600$ and $\$ 39,800$ respectively. The standard deviation $(S D)$, coefficient of variation $(C V)$ and $S D / f_{1}{ }^{*}$ were $\$ 505.96,0.0130$ and 0.0131 , respectively. $f_{1}{ }^{*}=$ $\$ 38,600$ is the cost of the optimal solution. It can be seen that the values of $C V$ and $S D / f_{1}^{*}$ are small and similar. $C V$ is indicative of the consistency of the results whereas $S D / f_{1}{ }^{*}$ is indicative of the quality of the results; self-evidently the smaller the values and the more the similarity, the better. Several near-optimal solutions 
were also found by the $10 \mathrm{GA}$ runs as shown in Table 2 .

\subsection{LOOPED DESIGN OF NETWORK 1}

Network 1 was also optimized as a looped network. Two different optimal layouts each with an associated optimal design (Designs 1 and 2) were created (Figure 5 and Table 3). Figure 6 shows the best POF achieved. As all hydraulically and topologically feasible designs have an infeasibility value of zero the nondomination sorting procedure ensures that only the cheapest feasible design can survive at the feasibility boundary as the least cost looped design. There are a few hydraulically feasible branched designs next to the least cost looped design (Figure 6). The maximum infeasibility value of 258 is the sum of the nodal head deficit for all nodes with insufficient pressure and supply paths shortfall for all nodes with less than two independent supply paths. Since all of the 8 demand nodes in this design are not connected to the source node the first term of Equation (7) results in a residual head deficit of $8 \times 30=240 \mathrm{~m}$. In addition, all 9 network nodes contribute a further infeasibility value of $9 \times 2=18$ through the second term in Equation (7). Inherently, infeasible solutions dominate the POF (Figure 6); all feasible solutions except for the cheapest are dominated as explained above.

Using a population of 100 , the GA was run 20 times due to the increased problem complexity and larger solution space using different randomly created initial populations. The complexity arises from the existence of alternative feasible flow distributions for looped networks. A maximum of 200,000 function evaluations per GA run were allowed. Interestingly, two different optimum designs having a

cost of $f_{1}^{*}=\$ 41,400$ were found (Designs 1 and 2 in Table 3). Designs 1 and 2 
were achieved after 5,000 and 10,500 function evaluations respectively. The CPU time was about 4.8s and 10.1s for Designs 1 and 2 respectively. Designs 1, 2 and 3 in Table 3 were identified 5, 3, and 10 times respectively by the 20 random GA runs. Each of Designs 4 and 5 in Table 3 was found once. The average, median and maximum value of the least cost were $\$ 41,885, \$ 42,200$ and $\$ 42,300$ respectively. The $S D, C V$ and $S D / f_{1}^{*}$ values were $\$ 406.88 .96,0.0097$ and 0.0098, respectively. It is worth highlighting that the least cost branched design of this network having a cost of $\$ 38,600$ was identified 13 times by the 20 GA runs. This result is significant in that it suggests it may be possible to combine and solve the branched and looped least cost network design problems together.

\subsection{BRANCHED DESIGN OF NETWORK 2}

Tables 4 and 5 and Figure 7 show the results for the branched design of Network 2. The solution of $\$ 1,684,228$ (Design 1) is the cheapest design to date while the near-optimal solution of $\$ 1,692,058$ (Design 2) is also cheaper than the best solution in the literature. The layout of Design 1 has not been identified previously. Its creation here is, therefore, a remarkable achievement. Two singlesource branched networks were created by removing 19 pipes (51\%) out of 37 in each of Designs 1 and 2. 20 GA runs were performed using different randomly created initial populations. The termination criterion was 500,000 function evaluations. The least cost of $f_{1}{ }^{*}=\$ 1,684,228$ (Design 1) was identified two times out of 20 . Using a population of 100 , this required 154,500 function evaluations and a CPU time of about 2.12 minutes according to the best POF. Design 2 was identified once among the 20 runs. The average, median and maximum values of the least cost were $\$ 1,753,359, \$ 1,733,044$ and $\$ 1,889,386$ respectively. The $S D$,

$C V$ and $S D / f_{1}{ }^{*}$ values were $\$ 60,731.81,0.0346$ and 0.0361 , respectively. Figure 8 
shows the best achieved POF. A good distribution of solutions is evident. This may be attributable to the larger solution space made up of a large number of branched layouts and pipe size combinations.

\subsection{LOOPED DESIGN OF NETWORK 2}

Tables 6 to 8 and Figure 9 show the results for the looped design of Network 2 . Remarkably, three new feasible solutions that are cheaper than the previous best solution in the literature were created. A new layout was created also, as shown in Figure $9 \mathrm{~b}$. The new layout is that of the new cheapest solution of $f_{1}{ }^{*}=\$ 1,972,559$ (Design 3) that has only 25 pipes. The previous best solution has 26 pipes (Figure 9a). 20 random runs of the GA using different starting points were performed. Using a population of 100 , the cheapest design of $\$ 1,972,559$ was identified two times out of 20 the best of which took 901,300 function evaluations. This took a CPU time of about 12.41 minutes. Two of the 20 runs resulted in Near-optimal Designs 1 and 2 respectively. The termination criterion was 1,000,000 function evaluations. The average, median and maximum values of the least cost were $\$ 2,019,891, \$ 1,998,076$ and $\$ 2,095,167$ respectively. The $S D, C V$ and $S D / f_{1}^{*}$ values were $\$ 43,683.82,0.0216$ and 0.0222 .

Figure 10 shows the best POF achieved; Figure 11 shows the full set and demonstrates the consistency and stability of the GA. For the topologically infeasible solutions the increase in cost is relatively gentle as the overall hydraulic performance improves while the infeasibility measure is decreasing. For the feasible branched solutions, the cost increases sharply as more pipes are added to create loops. A number of hydraulically feasible branched solutions lie near the cost axis, between the infeasible solutions and the least cost looped solution that 
has zero infeasibility. The cheapest feasible branched solution among the 20 conducted GA runs has a cost of $\$ 1,694,966$, which is slightly more expensive than the cheapest branched design of $\$ 1,684,228$ (Tables 4 and 5).

\section{CONCLUSIONS}

This article provides strong evidence to support the incorporation of infeasible solutions in the design optimization of water distribution networks. Arbitrarily penalizing or removing hydraulically or topologically infeasible solutions can lead to the loss of some essential features of the optimal solution from the gene pool. By contrast, the penalty-free fully inclusive approach developed does not avoid infeasible solutions and retains the advantage of progressing towards the optimum solution from both the feasible and infeasible sections of the solution space. It is believed the performance of the algorithm is enhanced in this way by virtue of the presence of both feasible and infeasible non-dominated near-optimal solutions in successive generations. For problems involving layout optimization, a procedure for handling topologically infeasible solutions in a rational manner is a precondition if the entire solution space is to be exploited in full. We addressed this issue in this article.

The benefits of solving the layout and pipe size optimization problems simultaneously rather than sequentially has been demonstrated. The results show that the present approach is efficient and yields good results consistently. Three benchmark problems in the literature were considered and in each case we found a new best solution. In all, six new feasible solutions that are cheaper than the best in the literature were found. The results suggest further improvements may be achieved by combining and solving the branched and looped design optimization problems together. A weakness of the proposed formulation is that it yields only 
the least cost feasible solution. Besides cost, a possible remedy might include the introduction of additional hydraulic performance objectives in order to differentiate the feasible solutions further. In addition, design should be based on minimizing the whole-life costs rather than the initial construction cost only. It is recognised also that the infeasibility measure adopted is dimensionally inconsistent. Further improvements are thus indicated.

\section{REFERENCES}

Afshar, M.H., Akbari, M., and Marino, M.A. (2005a) Simultaneous layout and size optimization of water distribution networks: engineering approach. J. Infrastruct. Syst., 11(4), 221-230.

Afshar, M.H. (2005b) Application of max-min ant system for joint layout and size optimization of pipe networks. Proceedings of 9th international water technology conference. IWTC9, 17-20 March, Sharm El-Sheikh, Egypt, 593-608.

Afshar, M.H. and Jabbari, Ibrahim (2007a) Simultaneous layout and size optimization of pipe networks using genetic algorithms. Arabian J. Sci. and Eng., 33(2B), 391-409.

Afshar, M.H. (2007b) Evaluation of selection algorithms for Simultaneous layout and size optimization of water distribution networks. Scientia Iranica, 14(1), 23-32.

Cembrowicz, R.G. (1992) Water Supply Systems Optimization for Developing Countries. In: B. Coulbeck and E. Evans, eds. Pipeline Systems (Fluid Mechanics and its Applications). Kluwer Academic, London, UK, 59-76.

Davidson, J.W. and Goulter, I.C. (1995) Evolution Program for Design of Rectilinear Branched Networks. J. Comp. in Civ. Eng., 9(2), 112-121.

Deb, K., Pratap, A., Agarwal, S. and Meyarivan, T. (2002) A Fast and Elitist Multiobjective Genetic Algorithm: NSGA-II. IEEE Trans. on Evo. Comp., 6(2), 182-197.

Djebedjian, B., Yaseen, A. and Ezzeldin. R. (2008) Reliability-Based Optimization of Layout and Sizing of Water Distribution Systems. Proceedings of the 12th International Water Technology Conference. IWTC12, 27-30 March, Alexandria. Egypt, 759-779.

Geem, Z.W., Kim, J.H., and Yoon, Y.N. (2000) Optimal Layout of Pipe Networks Using Harmony Search. Proceedings of $4^{\text {th }}$ International Conference on Hydro-Science and Engineering. 26-29 September, Seoul, South Korea.

Goldberg, D. E. (1989) Genetic algorithms in search, optimization and machine learning. 1st ed. USA: Addison-Wesley Longman Publishing Co.

Kessler, A., Ormsbee, L., and Shamir, U. (1990) A Methodology for Least-Cost Design of Invulnerable Water Distribution Networks. Civ. Eng. Syst., 7(1), 20-28.

Morgan, D.R. and Goulter, I.C. (1982) Least cost layout and design of looped water distribution systems. Proceedings of $9^{\text {th }}$ International Symposium on Urban Hydrology, Hydraulics and Sediment control. University of Kentucky, Lexington, KY, USA, 27-30.

Morgan, D.R. and Goulter, I.C. (1985) Optimal Urban Water Distribution Design. Water Resour. Research, 21(5), 642-652. 
Ofwat (2008) Guaranteed Standard Schemes [online]. Ofwat. Available from: http://www.ofwat.gov.uk/consumerissues/rightsresponsibilities/waterpressure [Accessed 29 January 2012].

Rossman, L.A. (2000) EPANET 2: Users Manual. Cincinnati, USA: U.S. Environmental Protection Agency.

Rowel, W.F. and Barnes, J.W. (1982) Obtaining the Layout of Water Distribution Systems. J. Hydraulics Division, 108(1), 137-148.

Shang, F. Uber, J.G. and Rossman, L.A. (2008) Modelling reaction and transport of multiple species in water distribution systems. Env. Sc. and Tech. 42(3), 808-814.

Siew, C. and Tanyimboh, T.T. (2012) Pressure-dependent EPANET extension. Water Resources Management, 26(6), 1477-1498.

Swamee, Prabhata K. and Sharma, Ashock K. (2008) Design of Water Supply Pipe Networks. New Jersey: John Wiley \& Sons.

Tanyimboh, T.T. and Kalungi, P. (2008) Optimal long-term design, rehabilitation and upgrading of water distribution networks. Engineering Optimization, 40(7), 637-654.

Tanyimboh, T.T. and Sheahan, C. (2002) A maximum entropy based approach to the layout optimization of water distribution systems. Civ. Eng. and Environ. Syst., 19(3), 223-253.

Tanyimboh, T.T. and Setiadi, Y. (2008) Joint layout, pipe size and hydraulic reliability optimization of water distribution systems. Eng. Optim., 40(8), 729-747.

Tanyimboh, T.T. and Templeman, A.B. (2010) Seamless pressure-deficient water distribution system model. J Water Manag, 163(8), 389-396.

Walters, G.A. and Lohbeck, T.K. (1993) Optimal Layout of Tree Networks Using Genetic Algorithms. Eng. Optim., 22(1), 27-48.

Walters, G.A. and Smith, D.K. (1995) Evolutionary Design Algorithm for Optimal Layout of Tree Networks. Eng. Optim., 24(4), 261-281. 


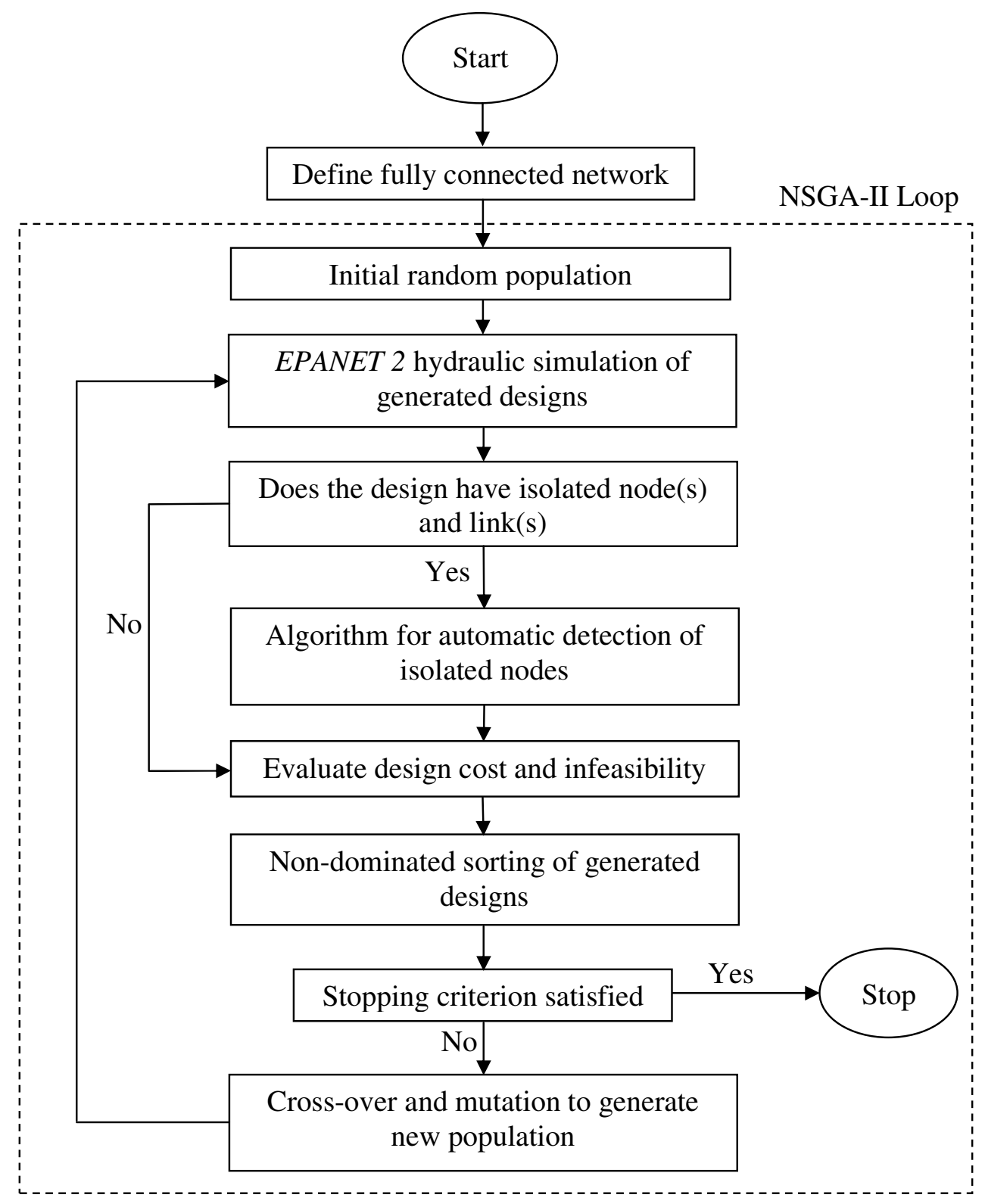

Figure 1: Diagrammatic overview of proposed approach 


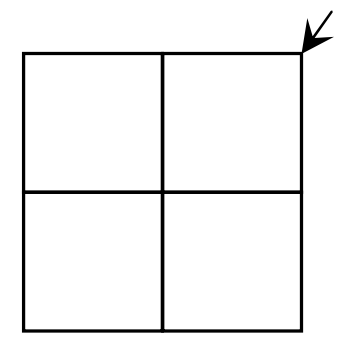

(a) Network 1

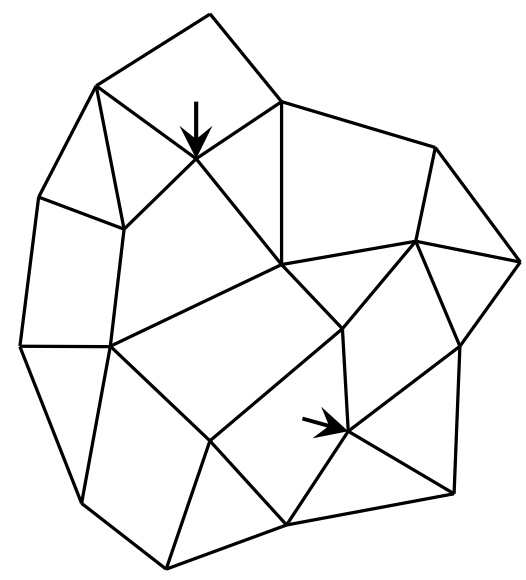

(b) Network 2

Figure 2: Topologies of benchmark networks solved 


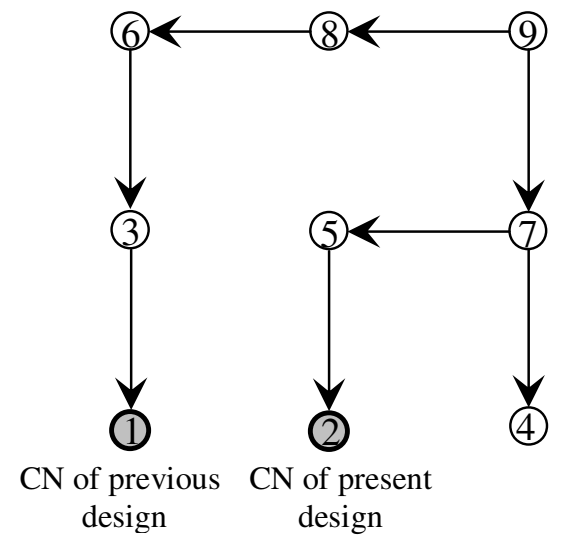

Figure 3: Optimal branched layout for Network 1 (CN denotes Critical Node) 


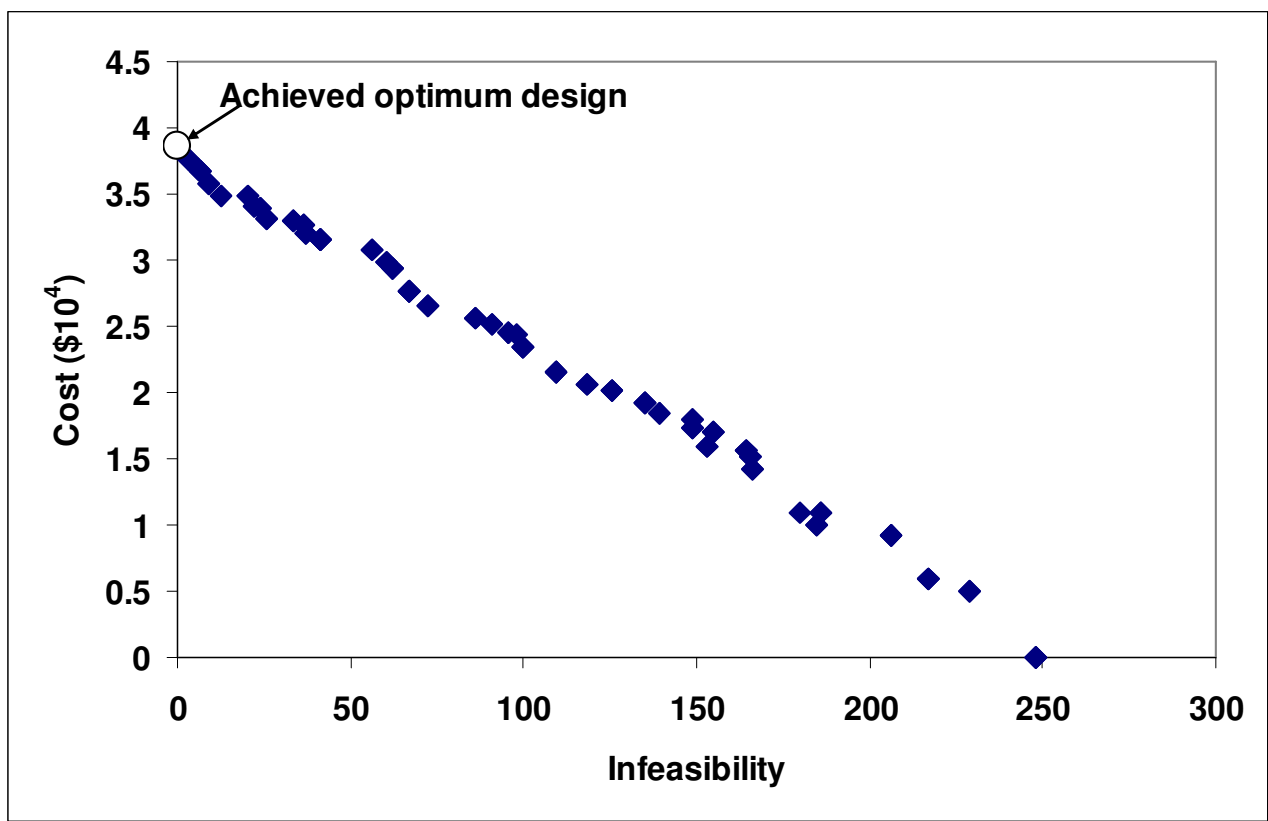

Figure 4: Best achieved Pareto optimal front for the branched design of Network 1 

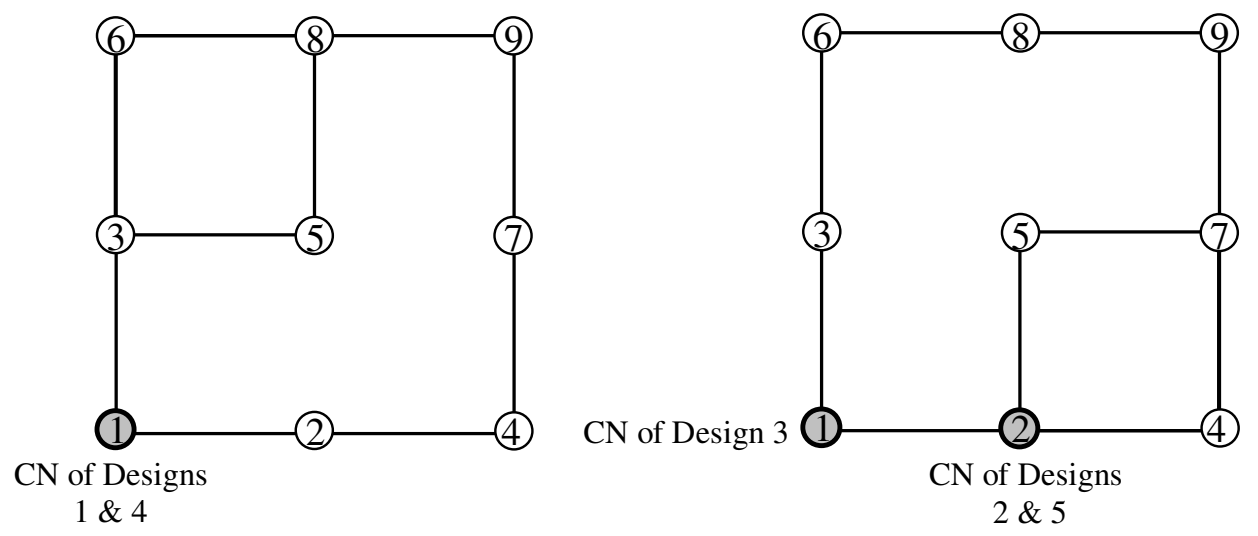

(a)

(b)

Figure 5: Optimal looped layouts for Network 1 (CN denotes Critical Node) 


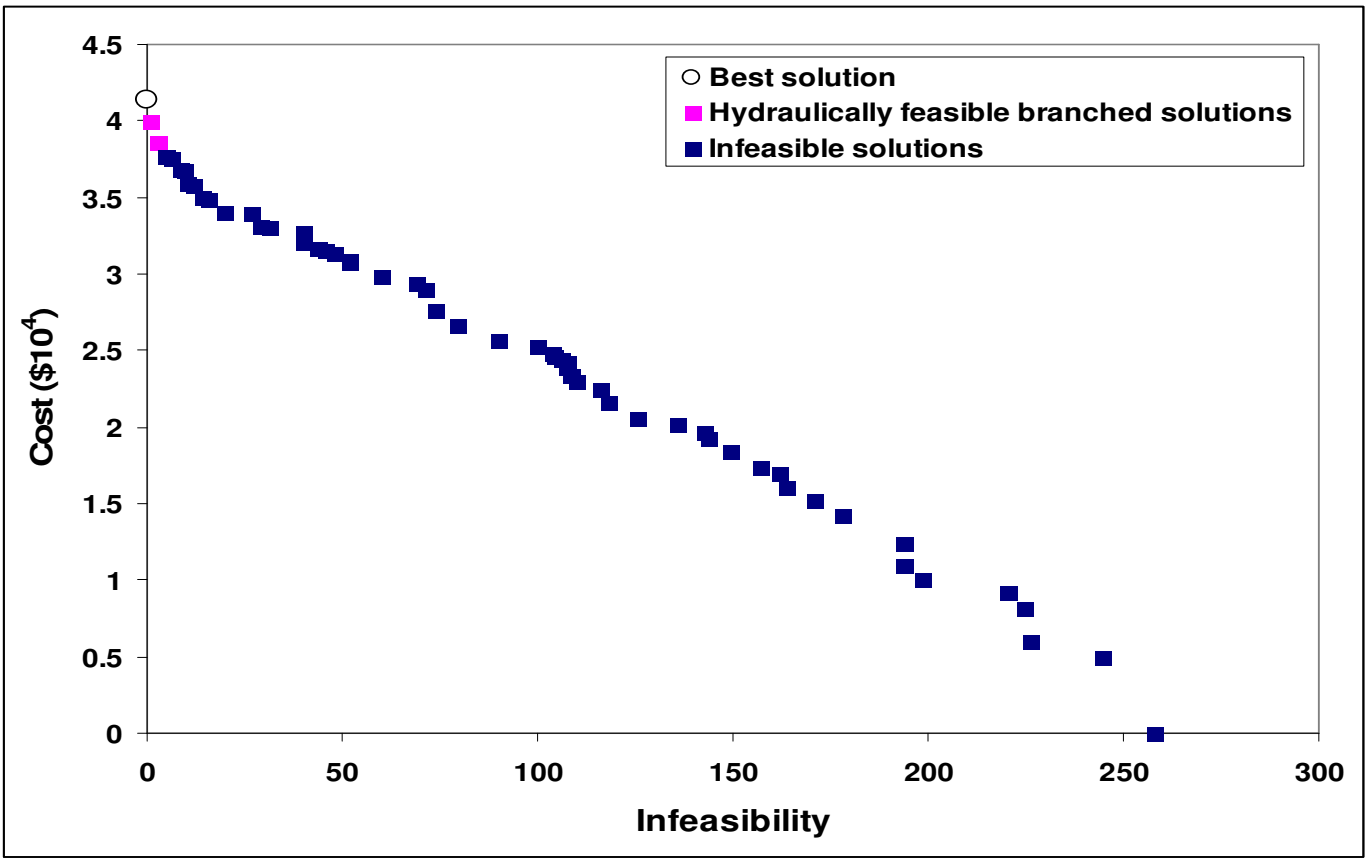

Figure 6: Best achieved Pareto optimal front for the looped design of Network 1 


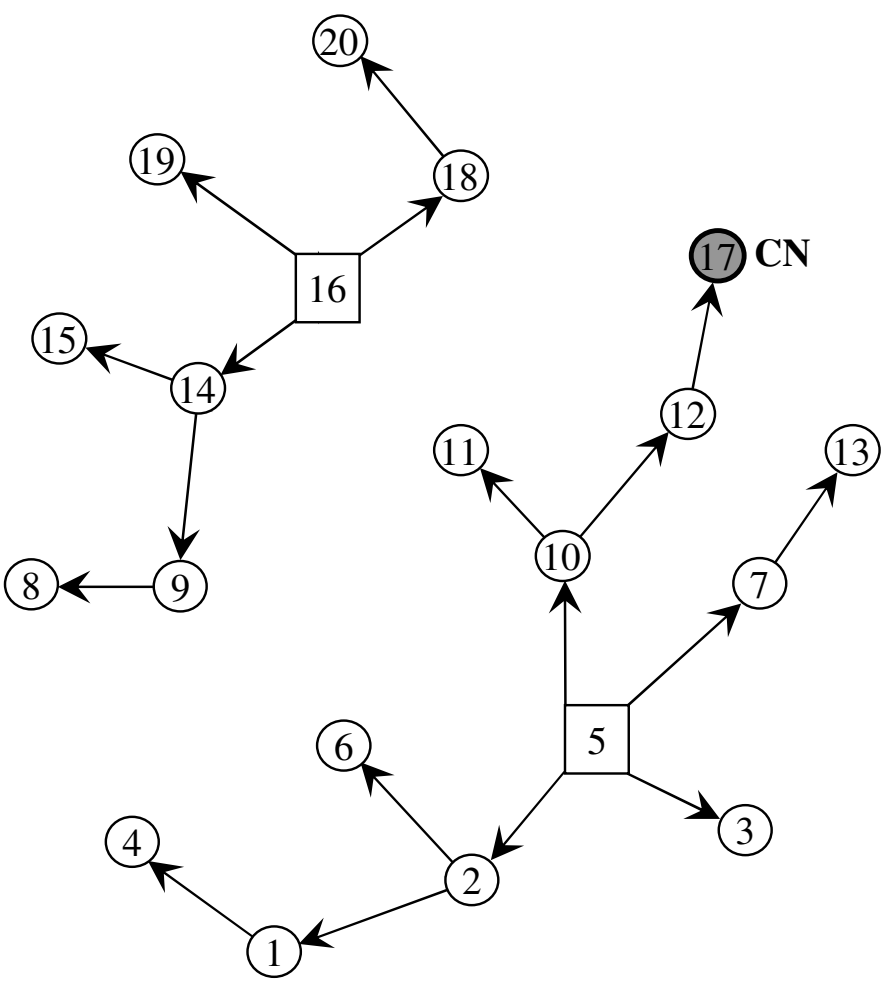

(a) New best solution

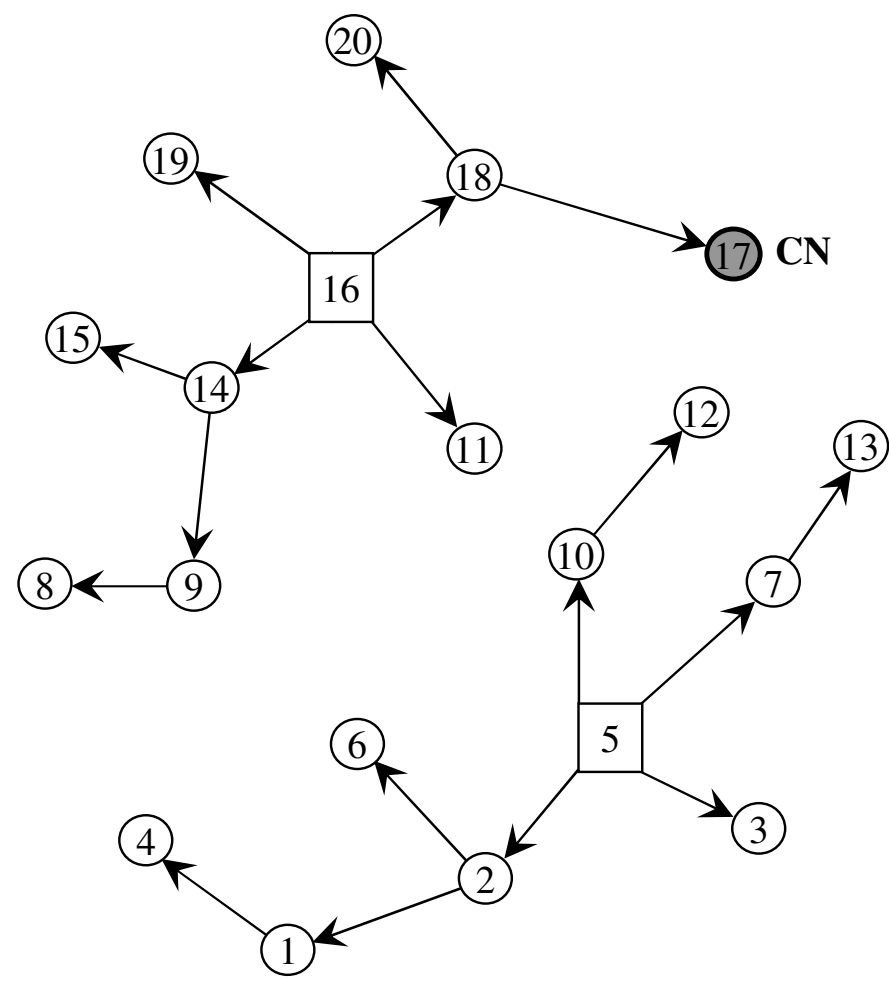

(b) Previous best solution (Afshar et al. 2005)

Figure 7: Optimal branched layouts for Network 2 (CN denotes Critical Node) 


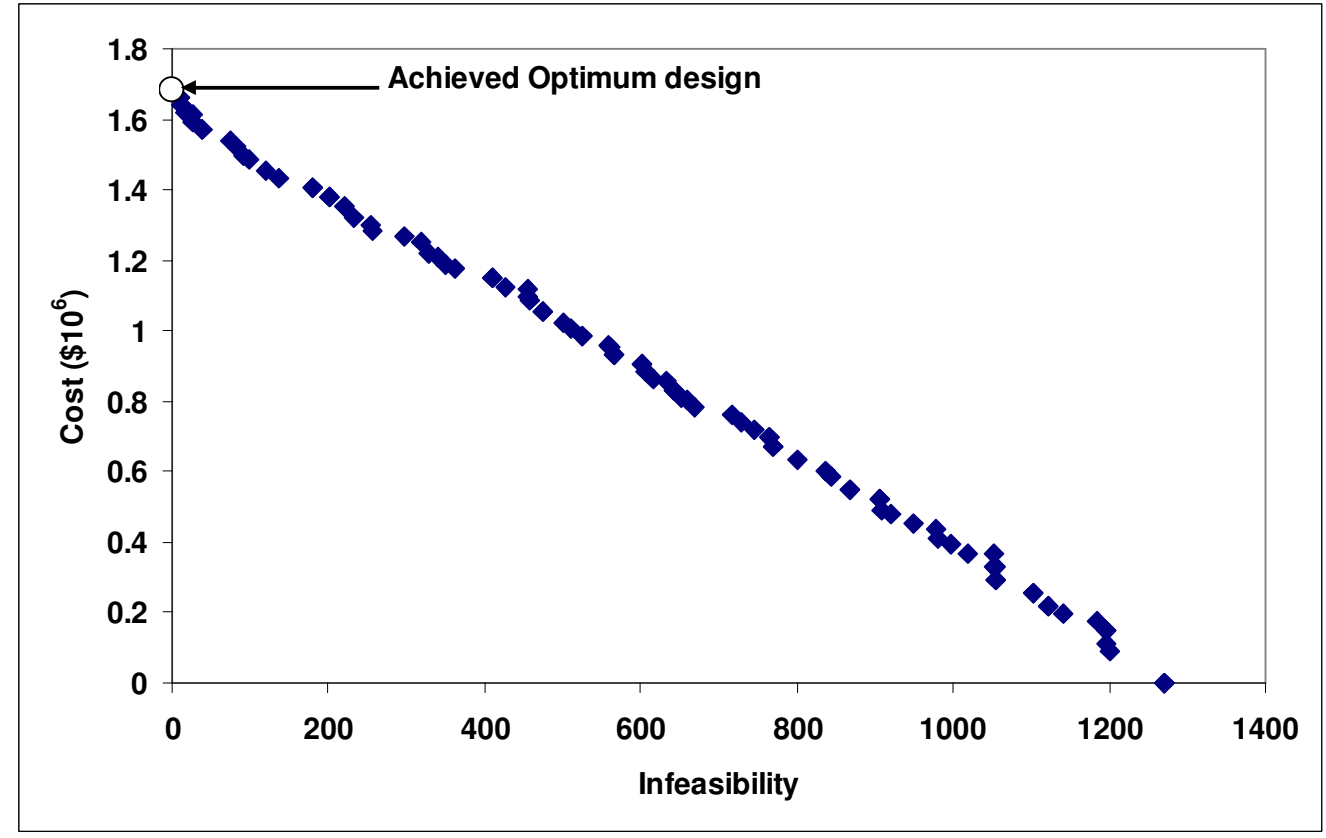

Figure 8: Best achieved Pareto optimal front for the branched design of Network 2 


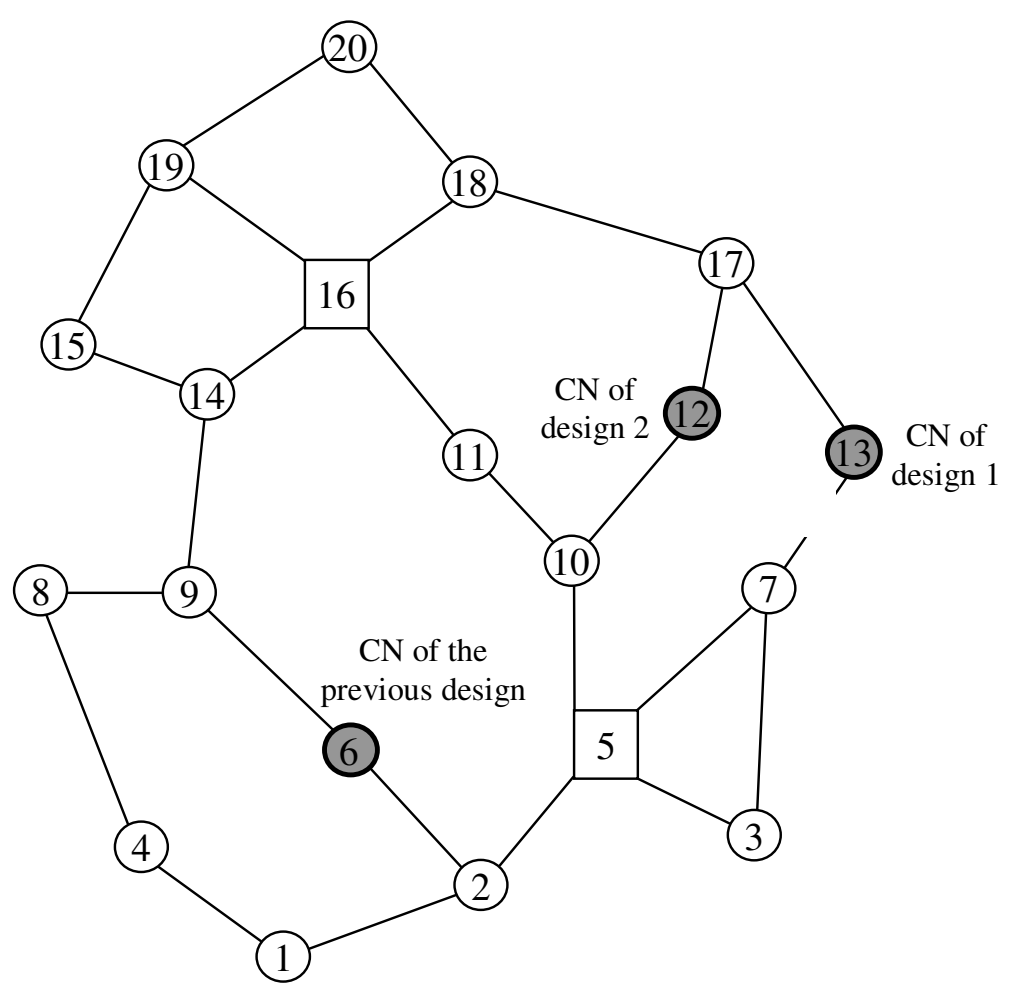

(a)

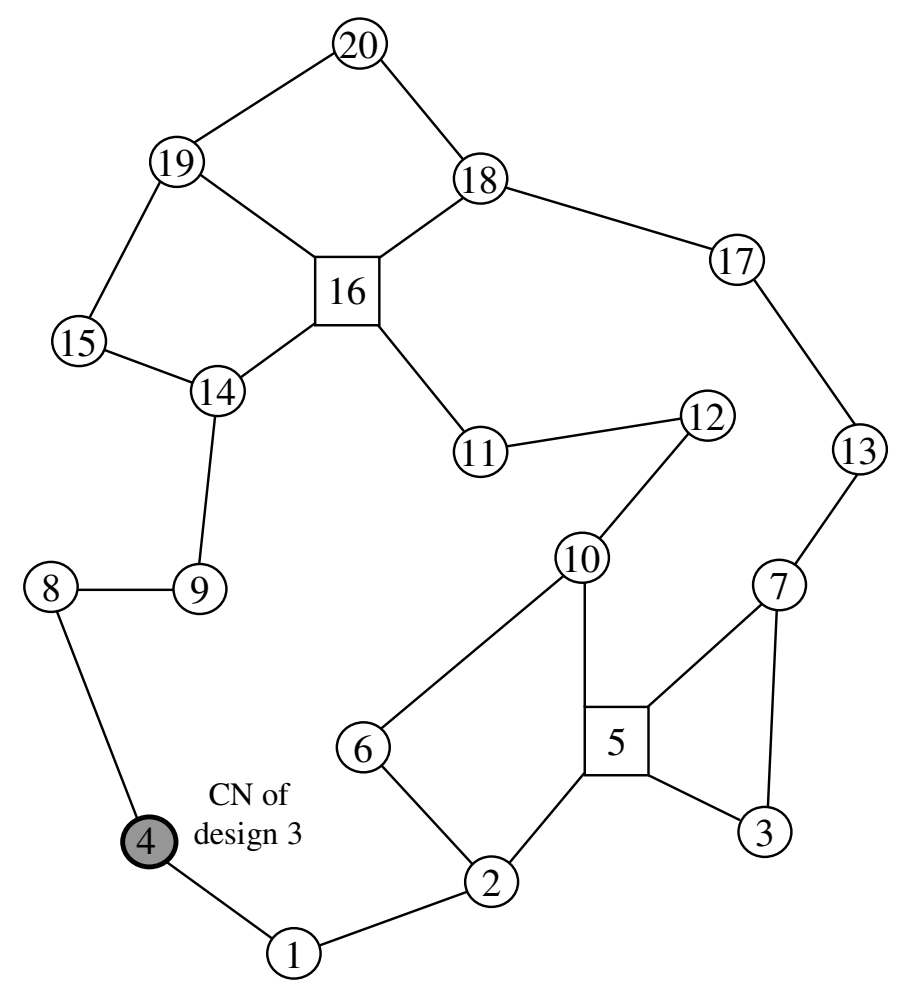

(b)

Figure 9: Optimal looped layouts for Network 2 (CN denotes Critical Node) 


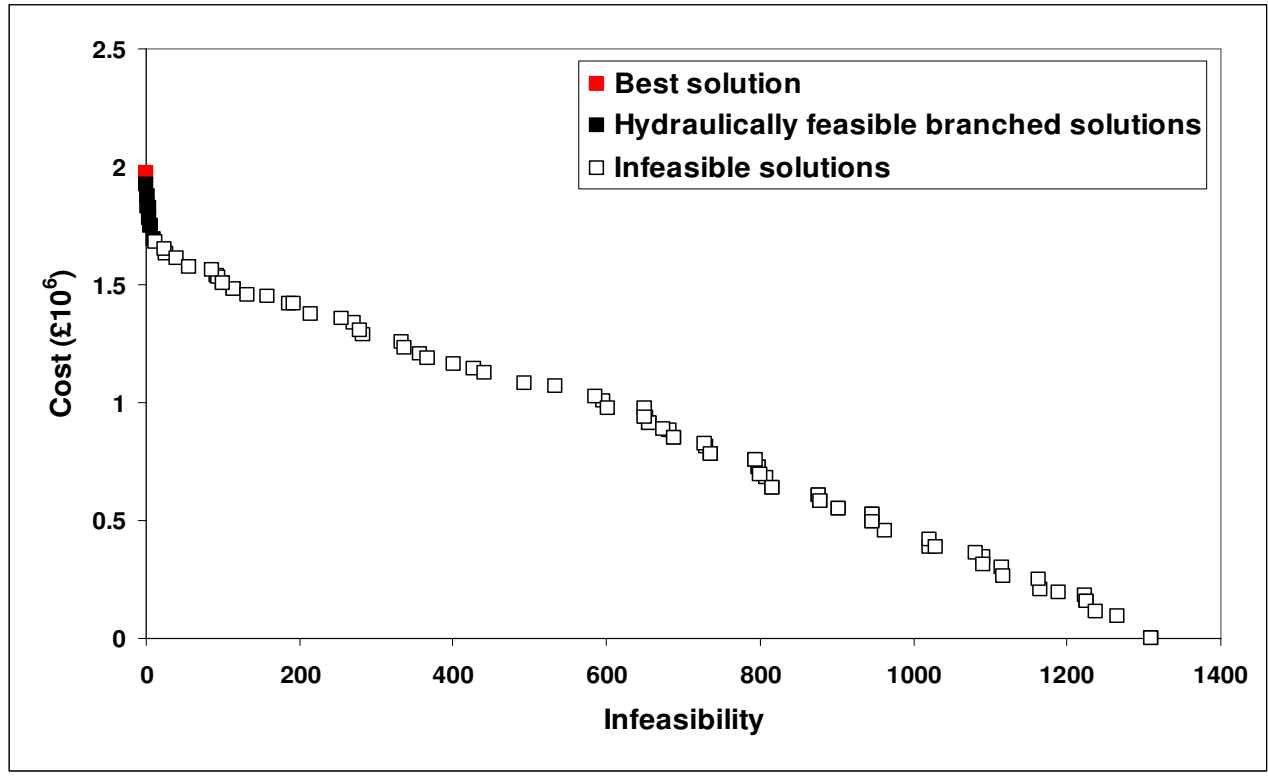

Figure 10: Best achieved Pareto optimal front for the looped design of Network 2 


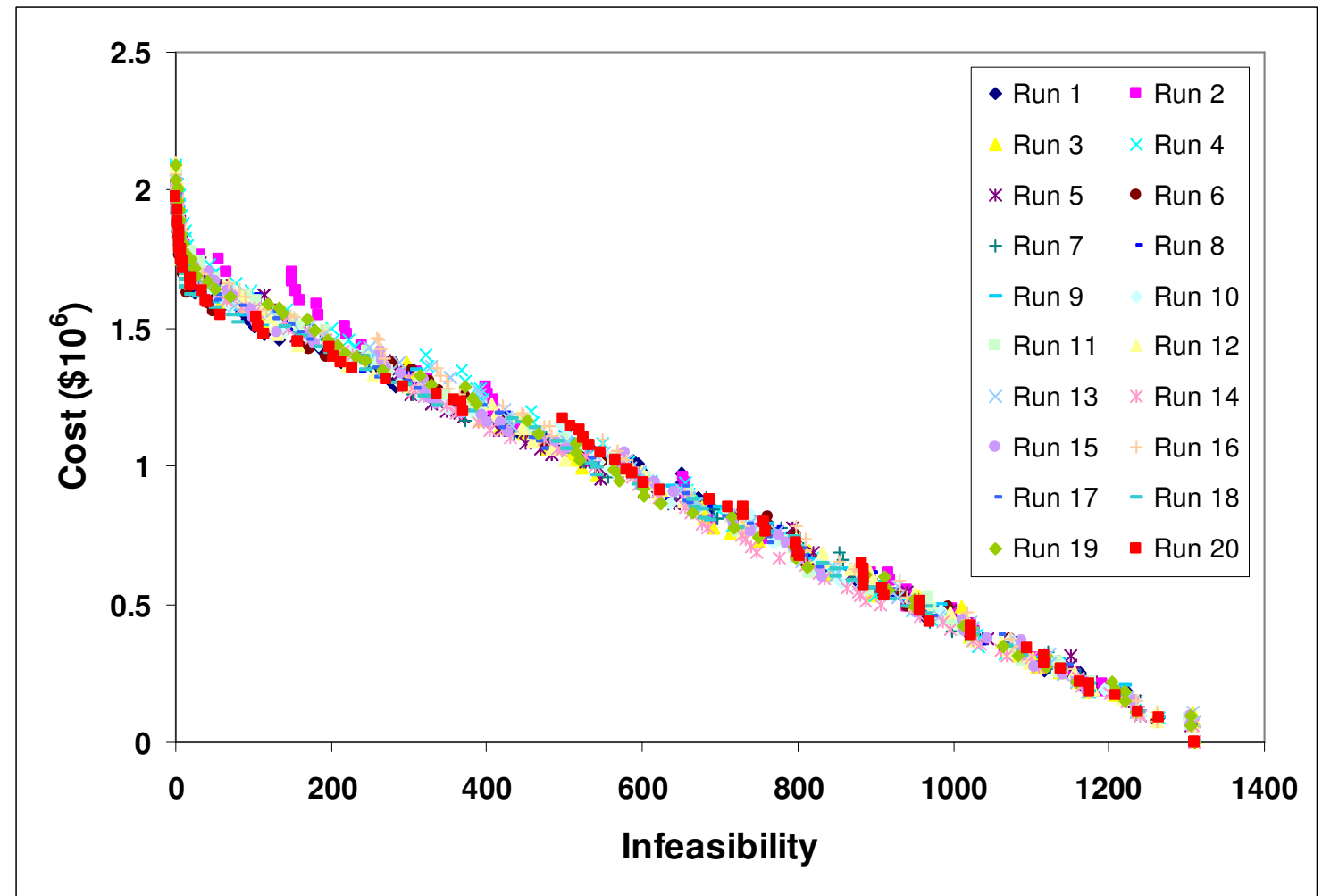

Figure 11: Consistency of the Pareto optimal fronts from the random GA runs for the looped design of Network 2 
Table 1: New and previous cheapest feasible branched designs for Network 1

\begin{tabular}{|c|c|c|c|c|c|c|c|}
\hline \multirow[b]{2}{*}{ Pipe } & \multicolumn{2}{|c|}{ Diameter (mm) } & \multirow[b]{2}{*}{ Node } & \multicolumn{2}{|c|}{ Head (m) } & \multicolumn{2}{|c|}{ Surplus head (m) } \\
\hline & $\begin{array}{l}\text { Afshar } \\
(2007 a)\end{array}$ & Present & & $\begin{array}{c}\text { Afshar } \\
\text { (2007a) }\end{array}$ & Present & $\begin{array}{l}\text { Afshar } \\
\text { (2007a) }\end{array}$ & Present \\
\hline $1-3$ & 100 & 100 & 1 & $30.21^{\mathrm{a}}$ & 30.21 & $0.21^{\mathrm{a}}$ & $0.21^{\mathrm{a}}$ \\
\hline $2-5$ & 120 & 100 & 2 & 30.94 & $30.06^{\mathrm{a}}$ & 0.94 & 0.06 \\
\hline $3-6$ & 120 & 120 & 3 & 32.12 & 32.12 & 0.12 & 0.12 \\
\hline $4-7$ & 100 & 100 & 4 & 32.89 & 32.90 & 0.89 & 0.90 \\
\hline $5-7$ & 120 & 140 & 5 & 33.78 & 36.94 & 0.78 & 0.94 \\
\hline $6-8$ & 140 & 140 & 6 & 34.95 & 34.95 & 0.95 & 0.95 \\
\hline $7-9$ & 140 & 140 & 7 & 39.78 & 39.77 & 0.78 & 0.77 \\
\hline $8-9$ & 140 & 140 & 8 & 39.78 & 39.77 & 0.78 & 0.77 \\
\hline
\end{tabular}


Table 2: Summary of the cheapest feasible branched and looped designs for Network 1

\begin{tabular}{|c|c|c|c|c|}
\hline Design Case & Author & Approach & Cost $(\$)$ & $\begin{array}{c}\text { Function } \\
\text { evaluations }\end{array}$ \\
\hline \multirow{9}{*}{ Branched } & $\begin{array}{l}\text { Geem et al } \\
\quad(2000)\end{array}$ & $\begin{array}{l}\text { Layout optimization followed by pipe } \\
\text { sizing using harmony search }\end{array}$ & 39,800 & $\mathrm{~N} / \mathrm{A}^{\mathrm{a}}$ \\
\hline & Afshar (2005b) & $\begin{array}{c}\text { Simultaneous layout and pipe size } \\
\text { optimization using max-min ant system }\end{array}$ & 39,800 & 7,900 \\
\hline & Afshar (2007a) & $\begin{array}{l}\text { Simultaneous layout and pipe size } \\
\text { optimization using GA with four } \\
\text { crossover selection schemes }\end{array}$ & 39,400 & 7,500 \\
\hline & Afshar (2007b) & $\begin{array}{c}\text { Simultaneous layout and pipe size } \\
\text { optimization using GA with three } \\
\text { crossover selection schemes } \\
\end{array}$ & 39,400 & 7,500 \\
\hline & \multirow{5}{*}{$\begin{array}{l}10 \text { random runs } \\
\text { of the proposed } \\
\text { approach }\end{array}$} & \multirow{5}{*}{ 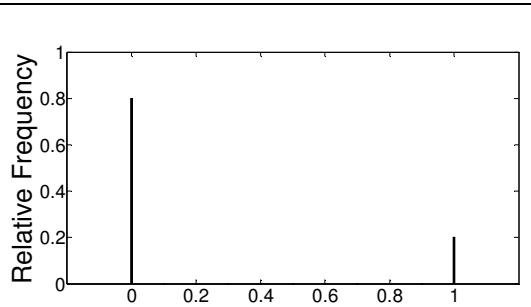 } & 39,800 & 9,500 \\
\hline & & & 39,700 & 9,900 \\
\hline & & & 39,600 & 21,100 \\
\hline & & & 39,400 & 28,200 \\
\hline & & & $38,600^{\mathrm{b}}$ & 10,400 \\
\hline \multirow{5}{*}{ Looped } & \multirow{5}{*}{$\begin{array}{l}20 \text { random runs } \\
\text { of the proposed } \\
\text { approach }\end{array}$} & \multirow{5}{*}{ 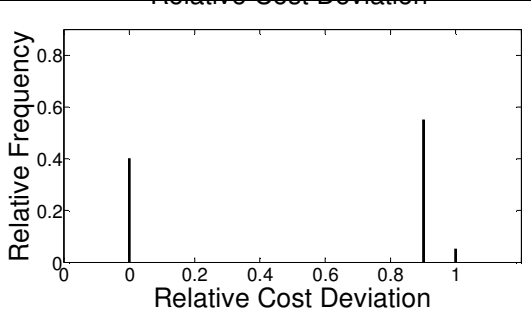 } & 42,300 & 198,100 \\
\hline & & & 42,200 & 112,100 \\
\hline & & & 42,200 & 7,200 \\
\hline & & & 41,400 & 10,500 \\
\hline & & & 41,400 & 5,000 \\
\hline
\end{tabular}

${ }^{\mathrm{a}} \mathrm{A}$ direct comparison is not possible as a hybrid approach involving a tree growing algorithm and harmony search was used. ${ }^{b}$ New best least-cost feasible solution 
Table 3: Results of the optimum looped designs achieved for Network 1

\begin{tabular}{|c|c|c|c|c|c|c|c|c|c|c|c|}
\hline \multirow{2}{*}{ Pipe } & \multicolumn{5}{|c|}{ Diameter (mm) } & \multirow{2}{*}{ Node } & \multicolumn{5}{|c|}{ Head (m) } \\
\hline & Des. 1 & Des. 2 & Des. 3 & Des. 4 & Des. 5 & & Des. 1 & Des. 2 & Des.3 & Des.4 & Des.5 \\
\hline $1-2$ & 100 & 80 & 80 & 100 & 80 & 1 & $30.04^{\mathrm{a}}$ & $30.13^{\mathrm{a}}$ & 30.07 & $30.07^{\mathrm{a}}$ & $30.03^{\mathrm{a}}$ \\
\hline $1-3$ & 80 & 100 & 100 & 80 & 80 & 2 & 31.26 & 30.66 & $30.06^{\mathrm{a}}$ & 30.67 & 31.00 \\
\hline $2-4$ & 140 & 100 & 80 & 120 & 80 & 3 & 30.37 & 31.18 & 32.02 & 31.41 & 32.33 \\
\hline $2-5$ & - & 80 & 100 & - & 100 & 4 & 33.72 & 35.00 & 30.76 & 35.08 & 33.69 \\
\hline $3-5$ & 100 & - & - & 80 & - & 5 & 32.25 & 33.70 & 34.99 & 33.67 & 36.17 \\
\hline $3-6$ & 80 & 100 & 120 & 100 & 100 & 6 & 30.72 & 36.40 & 34.88 & 32.82 & 36.96 \\
\hline $4-7$ & 140 & 140 & 100 & 140 & 120 & 7 & 40.44 & 38.88 & 39.81 & 41.18 & 38.52 \\
\hline $5-7$ & - & 100 & 120 & - & 140 & 8 & 39.08 & 40.63 & 39.73 & 38.27 & 40.95 \\
\hline $5-8$ & 100 & - & - & 100 & - & & & & & & \\
\hline $6-8$ & 100 & 140 & 140 & 120 & 140 & & & & & & \\
\hline $7-9$ & 140 & 140 & 140 & 140 & 140 & & & & & & \\
\hline $8-9$ & 140 & 140 & 140 & 140 & 140 & & & & & & \\
\hline $\operatorname{Cost}(\$)$ & 41,400 & 41,400 & 42,200 & 42,200 & 42,300 & & & & & & \\
\hline
\end{tabular}

${ }^{\mathrm{a}}$ Critical node 
Table 4: New and previous optimum branched designs for Network 2

\begin{tabular}{|c|c|c|c|c|c|c|c|c|c|c|}
\hline \multirow{3}{*}{ Pipe } & \multicolumn{3}{|c|}{ Diameter $(\mathrm{mm})$} & \multirow{3}{*}{ Node } & \multicolumn{3}{|c|}{ Head (m) } & \multicolumn{3}{|c|}{ Surplus head (m) } \\
\hline & \multirow{2}{*}{$\begin{array}{l}\text { Afshar } \\
(2005 a)\end{array}$} & \multicolumn{2}{|c|}{$\begin{array}{c}\text { Present } \\
\text { approach }\end{array}$} & & \multirow{2}{*}{$\begin{array}{l}\text { Afshar } \\
(2005 a)\end{array}$} & \multicolumn{2}{|c|}{$\begin{array}{c}\text { Present } \\
\text { approach }\end{array}$} & \multirow{2}{*}{$\begin{array}{l}\text { Afshar } \\
(2005 a)\end{array}$} & \multicolumn{2}{|c|}{$\begin{array}{l}\text { Present } \\
\text { approach }\end{array}$} \\
\hline & & $\begin{array}{c}\text { Des. } 1 \\
\text { (Fig. 10) }\end{array}$ & $\begin{array}{c}\text { Des. } 2 \\
\text { (Fig. 11) }\end{array}$ & & & Des. 1 & Des. 2 & & $\begin{array}{c}\text { Des. } \\
1\end{array}$ & $\begin{array}{c}\text { Des. } \\
2\end{array}$ \\
\hline $1-2$ & 400 & 400 & 400 & 1 & 83.68 & 79.37 & 83.69 & 8.68 & 4.37 & 8.69 \\
\hline $1-4$ & 300 & 350 & 300 & 2 & 94.67 & 90.34 & 94.67 & 20.67 & 16.34 & 20.67 \\
\hline $2-5$ & 550 & 500 & 500 & 3 & 80.85 & 80.85 & 80.86 & 7.85 & 7.85 & 7.86 \\
\hline $2-6$ & 250 & 300 & 250 & 4 & 75.23 & 75.38 & 75.25 & 3.23 & 3.38 & 3.25 \\
\hline $3-5$ & 250 & 250 & 250 & 5 & 102.00 & 102.00 & 102.00 & - & - & \\
\hline $5-7$ & 350 & 350 & 400 & 6 & 74.85 & 82.20 & 74.86 & 1.85 & 9.20 & 1.86 \\
\hline $5-10$ & 350 & 450 & 350 & 7 & 72.28 & 72.31 & 86.50 & 5.28 & 5.31 & 19.5 \\
\hline $7-13$ & 350 & 350 & 300 & 8 & 76.04 & 73.03 & 73.03 & 4.04 & 1.03 & 1.03 \\
\hline $8-9$ & 350 & 350 & 350 & 9 & 80.36 & 77.35 & 77.35 & 10.36 & 7.35 & 7.35 \\
\hline $9-14$ & 400 & 400 & 400 & 10 & 82.37 & 80.27 & 82.38 & 13.37 & 11.27 & 13.38 \\
\hline $10-11$ & - & 300 & - & 11 & 82.42 & 74.26 & 82.43 & 11.42 & 3.26 & 11.43 \\
\hline $10-12$ & 300 & 400 & 300 & 12 & 72.85 & 71.56 & 72.87 & 2.85 & 1.56 & 2.87 \\
\hline $11-16$ & 300 & - & 300 & 13 & 65.51 & 65.53 & 72.15 & 1.51 & 1.53 & 8.15 \\
\hline $12-17$ & - & 350 & - & 14 & 90.88 & 87.85 & 87.85 & 17.88 & 14.85 & 14.85 \\
\hline 14-15 & 250 & 300 & 300 & 15 & 74.32 & 81.05 & 81.05 & 1.32 & 8.05 & 8.05 \\
\hline 14-16 & 550 & 500 & 500 & 16 & 96.00 & 96.00 & 96.00 & - & - & \\
\hline $16-18$ & 400 & 350 & 400 & $17^{\mathrm{b}}$ & 67.15 & 67.34 & 67.17 & 0.15 & 0.34 & 0.17 \\
\hline 16-19 & 300 & 300 & 300 & 18 & 80.97 & 83.07 & 80.98 & 10.97 & 13.07 & 10.98 \\
\hline $17-18$ & 300 & - & 300 & 19 & 81.93 & 81.93 & 81.93 & 11.93 & 11.93 & 11.93 \\
\hline $18-20$ & 300 & 300 & 300 & 20 & 68.78 & 70.89 & 68.79 & 1.78 & 3.89 & 1.79 \\
\hline Cost $(\$)$ & $1,693,393$ & $1,684,228^{\mathrm{a}}$ & $1,692,058^{\mathrm{a}}$ & & & & & & & \\
\hline
\end{tabular}

${ }^{a}$ Two new best least cost feasible solutions. ${ }^{b}$ Critical node. 
Table 5: Summary of the new and previous optimal branched designs for Network 2

\begin{tabular}{|c|c|c|c|}
\hline Author & Approach & Cost $(\$)$ & $\begin{array}{l}\text { Function } \\
\text { evaluations }\end{array}$ \\
\hline Afshar (2007b) & $\begin{array}{lccc}\begin{array}{l}\text { Simultaneous layout and } \\
\text { optimization using }\end{array} \text { size } \\
\begin{array}{l}\text { with } \\
\text { crossover selection schemes }\end{array}\end{array}$ & $1,783,086$ & 100,000 \\
\hline Afshar (2007a) & $\begin{array}{l}\text { Simultaneous layout and pipe } \\
\text { optimization using GA } \\
\text { crossover selection schemes }\end{array}$ & $1,783,086$ & 100,000 \\
\hline Afshar (2005b) & $\begin{array}{l}\text { Simultaneous layout and pipe size } \\
\text { optimization using max-min ant system }\end{array}$ & $1,710,121$ & 22,800 \\
\hline Afshar (2005a) & \begin{tabular}{lccc} 
Iterative two-stage & \multicolumn{2}{c}{ procedure } & with \\
sequential layout and pipe & size \\
optimization & & & \\
\end{tabular} & $1,693,393$ & $N / A^{b}$ \\
\hline \multirow{2}{*}{$\begin{array}{l}20 \text { random runs of the } \\
\text { proposed approach }\end{array}$} & 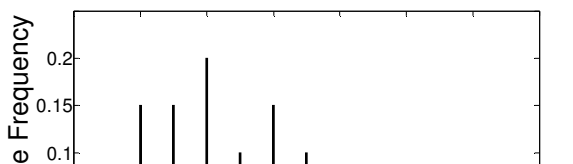 & $1,692,058^{\mathrm{a}}$ & 170,300 \\
\hline & 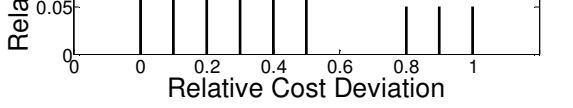 & $1,684,228^{\mathrm{a}}$ & 154,500 \\
\hline
\end{tabular}

${ }^{a}$ Two new best least cost feasible solutions. ${ }^{b}$ A direct comparison is not possible as two sequential stages incorporating an iterative search procedure were used. 
Table 6: New and previous optimal looped designs for Network 2

\begin{tabular}{|c|c|c|c|c|}
\hline \multirow{3}{*}{ Pipe } & \multicolumn{4}{|c|}{ Diameter $(\mathrm{mm})$} \\
\hline & \multirow{2}{*}{$\begin{array}{l}\text { Afshar } \\
(2005 a)\end{array}$} & \multicolumn{3}{|c|}{ Present approach } \\
\hline & & Design $1^{\mathrm{a}}$ & Design $2^{\mathrm{a}}$ & Design $3^{a}$ \\
\hline $1-2$ & 400 & 400 & 400 & 400 \\
\hline $1-4$ & 350 & 300 & 300 & 300 \\
\hline $2-5$ & 500 & 500 & 500 & 500 \\
\hline $2-6$ & 250 & 250 & 250 & 250 \\
\hline $3-5$ & 250 & 250 & 250 & 250 \\
\hline $3-7$ & 125 & 200 & 125 & 125 \\
\hline $4-8$ & 125 & 125 & 125 & 125 \\
\hline $5-7$ & 350 & 350 & 350 & 400 \\
\hline $5-10$ & 350 & 400 & 350 & 350 \\
\hline $6-9$ & 125 & 125 & 125 & - \\
\hline $6-10$ & - & - & - & 150 \\
\hline $7-13$ & 300 & 300 & 300 & 300 \\
\hline $8-9$ & 350 & 400 & 350 & 350 \\
\hline $8-15$ & - & - & - & - \\
\hline $9-14$ & 400 & 400 & 400 & 400 \\
\hline $10-11$ & 150 & 250 & 150 & - \\
\hline $10-12$ & 300 & 300 & 300 & 250 \\
\hline $11-12$ & - & - & - & 200 \\
\hline $11-16$ & 250 & 150 & 250 & 300 \\
\hline $12-17$ & 125 & 150 & 125 & - \\
\hline 13-17 & 125 & 150 & 150 & 125 \\
\hline 14-15 & 350 & 250 & 250 & 250 \\
\hline 14-16 & 500 & 500 & 150 & 500 \\
\hline 15-19 & 150 & 125 & 125 & 125 \\
\hline 16-18 & 450 & 400 & 450 & 400 \\
\hline 16-19 & 250 & 300 & 300 & 300 \\
\hline $17-18$ & 300 & 300 & 300 & 300 \\
\hline $18-20$ & 300 & 300 & 250 & 300 \\
\hline 19-20 & 125 & 150 & 200 & 125 \\
\hline Cost (\$) & $1,983,935$ & $1,979,767$ & $1,974,644$ & $1,972,559$ \\
\hline
\end{tabular}

${ }^{\mathrm{a}}$ Three new best least cost feasible solutions 
Table 7: Nodal heads of the new and previous optimal looped designs of Network 2

\begin{tabular}{|c|c|c|c|c|c|c|c|c|}
\hline \multirow{3}{*}{ Node } & \multicolumn{4}{|c|}{ Head (m) } & \multicolumn{4}{|c|}{ Surplus head (m) } \\
\hline & \multirow{2}{*}{$\begin{array}{l}\text { Afshar } \\
(2005 a)\end{array}$} & \multicolumn{3}{|c|}{ Present approach } & \multirow{2}{*}{$\begin{array}{l}\text { Afshar } \\
(2005 a)\end{array}$} & \multicolumn{3}{|c|}{ Present approach } \\
\hline & & Des. 1 & Des. 2 & Des. 3 & & Des. 1 & Des. 2 & Des. 3 \\
\hline 1 & 79.07 & 80.14 & 80.27 & 80.30 & 4.07 & 5.14 & 5.27 & 5.30 \\
\hline 2 & 90.44 & 90.79 & 90.88 & 91.08 & 16.44 & 16.79 & 16.88 & 17.08 \\
\hline 3 & 78.56 & 77.25 & 78.95 & 82.69 & 5.56 & 4.25 & 5.95 & 9.69 \\
\hline 4 & 74.80 & 72.20 & 72.38 & 72.16 & 2.80 & 0.20 & 0.38 & $0.16^{\mathrm{a}}$ \\
\hline 5 & 102.00 & 102.00 & 102.00 & 102.00 & - & - & - & - \\
\hline 6 & 73.02 & 73.23 & 73.97 & 76.34 & $0.02^{\mathrm{a}}$ & 0.23 & 0.97 & 3.34 \\
\hline 7 & 74.65 & 76.34 & 76.12 & 85.51 & 7.65 & 9.34 & 9.12 & 18.51 \\
\hline 8 & 72.52 & 73.99 & 74.50 & 72.85 & 0.52 & 1.99 & 2.50 & 0.85 \\
\hline 9 & 76.58 & 76.37 & 79.10 & 77.32 & 6.58 & 6.37 & 9.10 & 7.32 \\
\hline 10 & 79.46 & 81.44 & 79.33 & 84.42 & 10.46 & 12.44 & 10.33 & 15.42 \\
\hline 11 & 72.72 & 72.19 & 72.68 & 76.10 & 1.72 & 1.19 & 1.68 & 5.10 \\
\hline 12 & 70.40 & 70.38 & 70.15 & 70.65 & 0.40 & 0.38 & $0.15^{\mathrm{a}}$ & 0.65 \\
\hline 13 & 68.37 & 64.00 & 64.34 & 70.40 & 4.37 & $0.00^{\mathrm{a}}$ & 0.34 & 6.40 \\
\hline 14 & 87.29 & 87.76 & 90.69 & 88.02 & 14.29 & 14.76 & 17.69 & 15.02 \\
\hline 15 & 78.57 & 73.23 & 74.96 & 73.57 & 5.57 & 0.23 & 1.96 & 0.57 \\
\hline 16 & 96.00 & 96.00 & 96.00 & 96.00 & - & - & - & - \\
\hline 17 & 71.15 & 67.83 & 70.53 & 68.96 & 4.15 & 0.83 & 3.53 & 1.96 \\
\hline 18 & 86.90 & 81.84 & 87.98 & 81.94 & 16.90 & 11.84 & 17.98 & 11.94 \\
\hline 19 & 70.79 & 78.01 & 75.83 & 78.73 & 0.79 & 8.01 & 5.83 & 8.73 \\
\hline 20 & 73.77 & 71.78 & 69.14 & 71.22 & 6.77 & 4.78 & 2.14 & 4.22 \\
\hline
\end{tabular}


Table 8: Summary of the new and previous least cost feasible looped designs of Network 2

\begin{tabular}{|c|c|c|c|}
\hline Author & Approach & Cost $(\$)$ & $\begin{array}{l}\text { Function } \\
\text { evaluations }\end{array}$ \\
\hline Afshar (2007b) & $\begin{array}{l}\text { Simultaneous layout and pipe size } \\
\text { optimization using GA with four crossover } \\
\text { selection schemes }\end{array}$ & $2,056,379$ & 100,000 \\
\hline Afshar (2007a) & $\begin{array}{l}\text { Simultaneous layout and pipe size } \\
\text { optimization using GA with three crossover } \\
\text { selection schemes }\end{array}$ & $2,056,379$ & 100,000 \\
\hline Afshar (2005b) & $\begin{array}{l}\text { Simultaneous layout and pipe size } \\
\text { optimization using max-min ant system }\end{array}$ & $2,055,917$ & 31,500 \\
\hline Afshar (2005a) & $\begin{array}{llll}\text { Iterative two } & \text { stage } & \text { procedure } & \text { with } \\
\text { sequential } & \text { layout and pipe } & \text { size } \\
\text { optimization } & & & \end{array}$ & $1,983,935$ & $\mathrm{NA}^{\mathrm{b}}$ \\
\hline \multirow{3}{*}{$\begin{array}{l}20 \text { random runs of the } \\
\text { proposed approach }\end{array}$} & \multirow{3}{*}{ 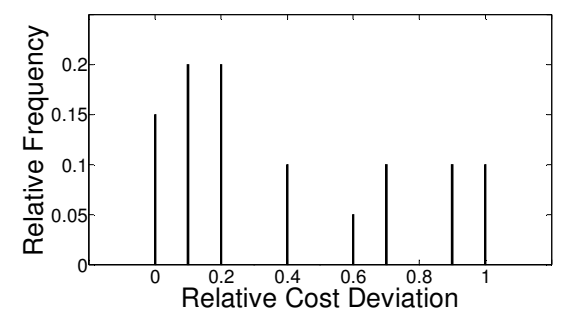 } & $1,979,767^{\mathrm{a}}$ & 370,500 \\
\hline & & $1,974,644^{\mathrm{a}}$ & 508,200 \\
\hline & & $1,972,559^{\mathrm{a}}$ & 901,300 \\
\hline
\end{tabular}

${ }^{\mathrm{a}}$ Three new best least cost feasible solutions. ${ }^{\mathrm{b}}$ A direct comparison is not possible as two sequential stages incorporating an iterative search procedure were used. 